\title{
Chance and the Prepared Mind - Attracting Trainees into Rheumatology
}

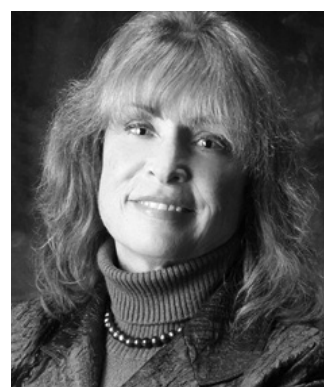

In the fields of observation, chance favors only the prepared mind.

— Louis Pasteur, University of Lille, December 7, 1854

What is the influence of a chance encounter in a training program? As the Rheumatology community grapples with the average age of practitioners in the mid-50s and a flat rate of already low recruitment of rheumatology trainees (RT) from internal medicine (IM) training programs, does type and timing of exposure to rheumatology have a predictive value?

In an intriguing article in this issue of The Journal ${ }^{1}$, Drs. Katz and Yacyshyn have data-mined the Canadian Post-MD Education Registry (CAPER) (which enables anonymous tracking of RT based on their IM residency training site), and examined the relationship of mere availability of a rheumatology rotation in each postgraduate year to the number of eventual RT generated. Curriculum information was obtained from the Canadian Residency Matching Service over a 3-year period; because programs were under major review during this period, no changes were likely to be implemented, assuring homogeneous atomic data.

Using advanced logistic regression techniques, Katz and Yacyshyn assigned the availability of a rheumatology elective a numeric value from 0 (no chance of completing a rotation over a given month) to 1 (mandatory completion). They address program restrictions in selectivity (a choice between rheumatology and another rotation would be 0.5), and accordingly, if rheumatology were one choice among 10 rotations, the score would be 0.1 . While statistical purists might argue the validity of this construct, it is an attempt to quantify existing data, as the number of rheumatology electives would not be considered a normally distributed value across IM training sites and in each postgraduate year, due to local variations in curriculum, full-time faculty equivalents, or participating community rheumatologists, as they ably demonstrate in their Table 1.
There was a positive relationship (Figure 1) between postgraduate year 1 rheumatology opportunities and subsequent entry into a Canadian rheumatology training program $(\mathrm{p}<0.033)$, with the coefficient of determination $\mathrm{r}^{2}=$ 0.3531 . These relationships were not significant for postgraduate years 2 and 3 . That the actual completion of the rheumatology rotation was not verified, but only a "surrogate variable" as the opportunity to have a rheumatology rotation was used, is a self-admitted weakness. A valid basis for further study with exact verification data would be anticipated to yield even more supportive results.

The data in this article for Canada (3.5\% of $651 \mathrm{IM}$ trainees from 13 accredited program sites entered a rheumatology training program) have validity in comparison with US IM program data for the same years (2005-2007): of the 384 accredited programs with 6408 IM trainees, the percentage entering a rheumatology training program is consistent at $2.7 \%, 2.7 \%, 2.8 \%$. The 2009 US data confirm a flat rate of $2.8 \%$ of IM trainees entering a rheumatology training program. Data are the same for US endocrinology, a comparable cognitive specialty, at $3.2 \%, 3.6 \%, 3.4 \%$; data for 2009 showed a slight increase, at $3.7 \%^{2}$.

Katz and Yacyshyn also showed that retention of IM trainees in their own rheumatology training program $(18 / 23$, or $78 \%)$ was the highest. While this varied across IM sites, the percentage for rheumatology was higher than for 4 comparator subspecialties, which ranged from $67 \%$ to $76 \%$. Rheumatology trainee retention was also highest when analyzed by institution. Other important factors that determine whether an IM postgraduate year 3 seeks rheumatology training program entry in his/her "home institution" or not (availability of trainee positions, effect of spouse/significant other/life partner status/job/children on staying or moving, and visa status) were not addressed in this report. With only 23 trainees to survey, these data are easily obtainable for future analysis. These factors are likely to be as strong determinants in individuals' choices to

See Attracting internal medicine trainees to rheumatology, page 2802

Personal non-commercial use only. The Journal of Rheumatology Copyright @ ${ }^{2009}$. All rights reserved. 
stay within their "home institution" as are the ease of moving self/family/home, etc. Incumbent bias is another factor - an onsite trainee, even if less qualified on paper than an external applicant, has an advantage because at some level he/she is known personally in the IM training program. While rheumatology training program directors are daily involved in local recruitment ex officio, the requirements of the Fellowship Match Programs also necessitate the consideration of all qualified applicants based on their site preferences and personal/family needs.

The word "enthusiasm" in its Greek origin is translated "a God within." All rheumatologists are aware of the important role they play through indirect mentoring by their exemplary and cogent history-taking, detailed physical examinations, integrative interpretations of complex immunologic/diagnostic test/imaging data, and demonstrated ability to dissect wide differential diagnoses to "solve the problem" and implement the appropriate layering of state of the art therapies inherent to our specialty. Our written, verbal, and healthcare information technologic communications to other providers also are exemplars. Direct mentoring of postgraduate year $1-3$ residents when partnering with them via inpatient consultations, referrals for outpatient consultations, and information exchange during comanagement through continuity clinics and/or ambulatory experiences in academic units or in local rheumatologists' practice sites offer other opportunities to vaunt our skills, enthusiasm, and satisfaction with our specialty. Our own American College of Rheumatology (ACR) and Research and Education Foundation Web pages document submissions from members worldwide who have shared how they came to be rheumatologists.

Data from an ongoing study kindly shared by Jack Cush, on how rheumatology trainees were "tractor beamed" to the field (personal communication, September 15, 2009), provide complementary data to the report of Katz and Yacyshyn ${ }^{1}$. While postgraduate year 1 was the crucial year of exposure, data from the first 428 respondents stated that $34.9 \%$ developed a rheumatology interest in medical school; $28.9 \%$ in postgraduate year 2 , and $19.4 \%$ in postgraduate year 3; the minority listed postgraduate year 1 (Kolazinski, et al showed $75 \%$ of IM trainees solidified their career choice in postgraduate year 1$)^{3}$. The most influential forces in the decision to enter a rheumatology training program were a rheumatology mentor who taught the trainee during residency $(52.7 \%)$; a rheumatology rotation $(32.5 \%)$; a rheumatologist/mentor from medical school (28.9\%); a mysterious/challenging patient seen in training $(27.9 \%)$; and advances in immunology relevant to rheumatology (21.6\%); while only $7.5 \%$ cited a rheumatology research project done in training. The lifestyle of a rheumatologist was listed as an inspiration/influence for $21.8 \%$ of $\mathrm{RT}^{4}$. The mixture of IM, chronic care, and clinical immunology were important components: $88.4 \%$ listed problem-solving as the most interest- ing aspect of rheumatology, 60\% physical examination skills, $58.6 \%$ expertise in diagnostic/laboratory testing, $47 \%$ lifestyle, and only $28.5 \%$ procedural skills.

Despite recognition that about $42 \%$ of patients seeking care in a family or IM practitioner's office have a chief complaint relevant to the musculoskeletal system, rheumatology as a specialty has few mandatory exposures in IM residencies in North America: most often, as in Canada, this is a 4-week elective in postgraduate year $2 / 3$. [Historically, rheumatology rotations are often less than 4 weeks of ambulatory/inpatient/emergency room consultation exposure due to scheduling of vacation/Fellowship/future position interview time during this rotation (often with the suggestion or blessing of the IM program directors, as well as coscheduling with other mandated experiences).] IM program directors need to support rheumatology directors by embracing, expounding upon, and exhibiting positive attitudes towards rheumatology program contributions to medical education and healthcare provision enterprise-wide as a cognitivebased specialty; the message some trainees "hear" from IM program directors is that all the other IM procedural specialties are "supporting rheumatology." Yet we are often called in late to consult on multisystem complex disease patients, when we should have been involved from admission. IM program directors need to impart to IM trainees that rheumatology is actively involved in healthcare advocacy reform for both patients and physicians through the ACR as well as our representatives to the American Medical Association, and the American College of Physicians, thus enhancing our communications back to our generalist colleagues from whom our referrals flow. Rheumatology has increased its use of healthcare information technology in alignment with national trends for patient safety, practice redesign, facilitation of quality improvement, and performance benchmarking, and its use of musculoskeletal ultrasonography, which can contribute to increased diagnostic specificity, therapeutic accuracy, and revenue generation.

Lastly, IM program directors should be aware that our national efforts to improve diagnostic autoimmune disease serologies by active input to laboratories and payors is resulting in improved and efficient serodiagnosis crucial for our patients and our specialty. Our rheumatology training program directors impart this knowledge during core course instruction, modular teaching, and rheumatology rotations with the help of Fellows, allied health personnel, and staff.

"I am on the edge of mysteries and the veil is getting thinner and thinner"; Louis Pasteur's words ${ }^{5}$ embrace the excitement of mentoring, problem-solving, and the ongoing advances in therapeutics that characterize rheumatology. I recall my own vectors into rheumatology, including the serendipity of geography (living in Durham, NC, USA); high school immunology research projects with C.H. Zmijewski and H.F. Seigler from Bernard Amos's laboratory; independent study projects as a Duke undergraduate in

Personal non-commercial use only. The Journal of Rheumatology Copyright (c) 2009. All rights reserved. 
psychology and neuroimmunology; team research projects in Duke Medical School with Wendell Rosse, and the Immunology Track Program with Ralph Snyderman that solidified my academic aspirations. Other enthusiastic mentors in clinical rheumatology, metabolic and genetic diseases, and bench researchers taught me willingly (W.N. Kelley, J.B. Wyngaarden, P.F. Pepe, W.J. Arnold, Grace P. Kerby, E.W. Holmes, J.R. Rice, D.S. Caldwell, B.F. Haynes, and D.S. Pisetsky). In both undergraduate and graduate medical education we must make every exposure to our specialty erudite, exciting, and exemplary. Our ACR Web page touts "fewer emergencies, more life/work/family balance" as characteristics that attract our current generation of replacements; however, the rare occasions where our most challenging patients require our extended input are among the most rewarding.

A high school volunteer is peering into my Infusion Center in between filing outside documents, watching me use real-time electronic medical records to document my patient encounter, and verify dosing and update medication orders with mouse clicks, and images, not strokes of the pen. I will ask him what his vision is for himself in healthcare, and I will listen for clues as to what enthralls him, just as Duke Medical Center faculty asked me when I was filing lab tests as a high school student and surreptitiously learning what studies doctors order for various conditions. It starts with a chance encounter... I thank the 106 Fellows who over 28 years in academia trained me (along with numerous IM residents and medical students).

The Rheumatology community worldwide looks forward to an extension to the report of Katz and Yacyshyn with details for analysis of correlations, as we all labor in our respective vineyards to provide opportunities for early diagnosis, new research advances that translate into treatment, and optimal outcomes for patients.

\author{
GALE A. MCCARTY, MD, FACP, FACR, \\ Chief of Rheumatology, \\ The Mary Dow Center, Suite 3600 , \\ Maine Coast Medical Center, \\ 50 Union Street, \\ Ellsworth, Maine 04605, USA
}

Dr. McCarty's Faculty Appointments at Eastern Maine Medical Center and Tufts NE Medical Center are in process.

Address correspondence to Dr. McCarty.

E-mail: gmccarty@mainehospital.org

\section{REFERENCES}

1. Katz SJ, Yacyshyn EA. Attracting internal medicine trainees to rheumatology - where and when program directors should focus efforts. J Rheumatol 2009;36:2802-5.

2. American Board of Internal Medicine. ACCGME accredited program. Roster, 2005-2009 [Internet.] Available from: www.abim.org

3. Kolazinski S, Bass AR, Kane-Wanger GF, Libman BS, Sandorfi N, Utset T. Subspecialty choice: Why did you become a rheumatologist? Arthritis Rheum 2007;57:1546-51.

4. Young Investigator Subcommittee of the American College of Rheumatology Committee on Research. Rheumatology fellows' perception on training and careers in academia: the American College of Rheumatology Fellow Research and Academic Training Survey. Arthritis Rheum 2009;61:266-73.

5. de Kruif P. The microbe hunters. New York: Harcourt, Brace; 1926.

J Rheumatol 2009;36:2627-9; doi:10.3899/jrheum.091106 